\title{
Enhanced Expression of an Exocrine Pancreatic Protein in Alzheimer's Disease and the Developing Human Brain
}

\author{
Suzanne M. de la Monte, Mehmet Ozturk, and Jack R. Wands \\ Molecular Hepatology Laboratory, Cancer Center, Massachusetts Alzheimer's Disease Research Center, \\ and Department of Pathology, Massachusetts General Hospital, Boston, Massachusetts 02114
}

\begin{abstract}
Pancreatic thread protein (PTP) is a major exocrine secretory protein that in vitro forms filamentous bundles reminiscent of the paired helical filaments of Alzheimer's disease (AD). We previously described increased PTP immunoreactivity in AD brains and now report high levels in the developing human brain. Using a full-length cloned bovine PTP cDNA and synthetic oligonucleotides corresponding to human PTP cDNA, which is identical to human islet cell regeneration factor, we analyzed the expression of PTP in pancreas and brain. A major 0.9-kb as well as several minor transcripts were identified in human pancreas. In AD brain, the same size transcripts were detected by Northern analysis, primer extension assay, or polymerase chain reaction amplification of $\mathrm{CDNAs}$ generated by reverse transcriptase assay. There were significantly higher levels of PTP mRNA in brains with AD compared with aged controls, with increased amounts of 1.2-, 0.6-, and 0.4-kb transcripts by Northern analysis. In situ hybridization localized expression to pyramidal neurons in the cerebral cortex, the same population that contains neurofibrillary tangles and high levels of immunoreactive PTP. These findings suggest that AD is associated with enhanced expression of PTP-related transcripts with intraneuronal accumulation of PTP-like proteins. (J. Clin. Invest. 1990. 86:1004-1013.) Key words: pancreatic thread protein • Alzheimer's disease $•$ Down's syndrome $\bullet$ central nervous system
\end{abstract}

\section{Introduction}

Alzheimer's disease is the most important cause of dementia in the United States, accounting for $50-60 \%$ of the cases (1). Neurodegeneration in Alzheimer's disease is characterized by the accumulation of neurofibrillary tangles in pyramidal neurons, aberrant neuritic sprouts and neurofibrils in the neuropil, neuritic plaques, amyloid deposition, and granulo-

Address reprint requests to Dr. de la Monte, Molecular Hepatology Laboratory, MGH East, 149 13th Street, 7th Floor, Charlestown, MA 02114.

Received for publication 30 March 1990 and in revised form 9 May 1990

J. Clin. Invest.

(c) The American Society for Clinical Investigation, Inc. $0021-9738 / 90 / 09 / 1004 / 10 \$ 2.00$

Volume 86, September 1990, 1004-1013 vacuolar degeneration of neurons. The pathogenesis of these lesions is unknown, but the same structural abnormalities occur in brains of all middle-age individuals with Down's syndrome, whether or not they are demented. Recently, we described in brains of patients with Alzheimer's disease or Down's syndrome, striking accumulation of a protein that shares three identical antigenic epitopes with an exocrine pancreatic thread protein (PTP) ${ }^{1}$ (2). PTP is a secretory protein derived from pancreatic acinar cells, and is found in pancreatic fluid in concentrations of milligrams per milliter (3-5). The physiologic function of PTP is not known. To explore the role of PTP expression in central nervous system disease, we cloned the bovine pancreatic cDNA by screening a pancreatic cDNA library using polyclonal antibody to purified bovine PTP (5), and performed hybridization studies as well as immunolabeling assays to examine expression in the human brain with respect to Alzheimer's disease and development.

\section{Methods}

Cloning of bovine PTP cDNA. We initially screened a bovine pancreatic cDNA library since the measured concentration of PTP in pancreatic fluid was $\sim 10^{6}$ times higher than that found in the normal brain or cerebrospinal fluid (CSF), and there is a high homology at the protein level between the human and bovine forms of the pancreatic protein (5). A bovine pancreatic cDNA library ligated into the EcoRI site of the $\lambda$ ZAP cloning vectors (gift from Dr. L. Lang, Washington University School of Medicine, St. Louis, MO) was screened (6) with polyclonal antibody to purified PTP $(3,5)$. Cloned inserts were sequenced by the dideoxynucleotide chain termination method (7) using plasmid DNA and T7 polymerase (Pharmacia LKB Biotech, Piscataway, $\mathrm{NJ}$ ).

PTP expression in bovine and human tissues. Total cellular RNA was extracted by the guanidinium thiocyanate- $\mathrm{CsCl}$ method (8). For Northern analysis, 10- $\mu \mathrm{g}$ samples of total RNA were electrophoresed through a $1.2 \%$ denaturing formaldehyde-agarose gel (9), transferred (10) to Nytran membranes (Schleicher \& Schuell, Inc., Keene, NH), and then baked for $2 \mathrm{~h}$ at $80^{\circ} \mathrm{C}$. Dot-blot hybridization studies were performed using $5 \mu \mathrm{g}$ of total cellular RNA spotted directly onto dry Nytran membranes in $5 \mu \mathrm{l}$ of $50 \%$ formamide/5× SSPE. The filters were air-dried and then baked for $2 \mathrm{~h}$ at $80^{\circ} \mathrm{C}$. Prehybridization was accomplished by equilibrating the filters in buffer containing $50 \%$ formamide, $5 \times$ SSPE, $5 \times$ Denhardt's solution, $0.1 \%$ SDS, and 100

1. Abbreviations used in this paper: CSF, cerebrospinal fluid; ICRF, islet cell regeneration factor; M-IRMA, monoclonal immunoradiometric assay; PCR, polymerase chain reaction; PTP, pancreatic thread protein. 
$\mu \mathrm{g} / \mathrm{ml}$ denatured salmon sperm DNA at $42^{\circ} \mathrm{C}$ for $2 \mathrm{~h}$. PTP mRNA was detected by hybridizing the filters for $12-16 \mathrm{~h}$ at $42^{\circ} \mathrm{C}$ in the same buffer plus probe $\left(10^{6} \mathrm{cpm} / \mathrm{ml}\right)$ corresponding to the 2-1 cloned $E c o R I$ insert encoding bovine PTP, labeled with $\left[\alpha{ }^{32} \mathrm{P}\right] \mathrm{dCTP}$ by the random priming method (Amersham Corp., Arlington Heights, IL). The blots were washed with a final stringency of $0.2 \times$ SSPE and $0.1 \%$ SDS at $60^{\circ} \mathrm{C}$. The hybridization signal was detected by autoradiography using X-OMAT AR film (Eastman Kodak Co., Rochester, NY) with Cronex Lightning Plus intensifying screens (DuPont Co., Wilmington, DE).

Comparison with other cDNA sequences in the Genebank database Release 62.0 disclosed that our cloned bovine PTP cDNA shares a high degree of homology with human and rat islet cell regeneration factor (ICRF) (11). Moreover, the deduced amino acid sequence of h-ICRF cDNA was found to be identical to the known partial amino acid sequence of human PTP (3) and pancreatic stone protein (4). We concluded that the h-ICRF cDNA was identical to human PTP cDNA, and therefore synthesized two 105mers (No. 1: 5'---CGA ATT CAT GTT CTG GCA ATA GAG ATC TGC ATC AAC CCA GGT CTC ACG GTC TTC ATT AAA GTA GTA GCA GTA GGA ACT GTA GGC ATT GGA ACC TTC TGG ACA AGT GAT---3'; No. 2: 5'--GCT CAC ACA GTA GCC AGG ATT AAC ACT GCT GCT TGG GGC TCC AAT GCC CCA GGA CTT GTA GGA GAC TAG GGA CCC ACT GCT CCA GTG CCA GCG GCG GTT CTT TTT---3') corresponding to internal sequences of $h-I C R F$ cDNA, in order to achieve more specific hybridization with human RNA, particularly that derived from the CNS, and two 30mers (No. 1: 5'--TAC GCC TTA AGT TCC AAA GAC TGG GGT AGG---3'; No. 2: 5'---GCG CGG ATT TCA TTG CAG CTC AGC ATG GCT---3') for more sensitive demonstration of PTP-related transcripts by primer extension and polymerase chain reaction (PCR) amplification. Both 30mers contain a single terminal EcoRI restriction site not present in the h-ICRF cDNA, but included to facilitate eventual subcloning.

Primer extension assay and PCR amplification. Primer extension assays $(12,13)$ were performed using total cellular RNA, $5^{\prime}$ end-labeled $\left[\gamma-{ }^{32} \mathrm{P}\right] \mathrm{ATP}$ no. 1 synthetic $30 \mathrm{mer}$ as the primer, and Avian reverse transcriptase (Promega Biotec, Madison, WI). The synthesized products were electrophoresed in a $1.2 \%$ alkaline-denaturing agarose gel and analyzed by autoradiography. PCR amplification (14) of specific PTP-related cDNAs was accomplished by generating first strand synthesis products using unlabeled no. $130 \mathrm{mer}$ as the primer, followed by 30 cycles of denaturation $\left(94^{\circ} \mathrm{C}\right.$ for $\left.1 \mathrm{~min}\right)$, annealing $\left(55^{\circ} \mathrm{C}\right.$ for 2 $\mathrm{min})$, and extension $\left(72^{\circ} \mathrm{C}\right.$ for $\left.3 \mathrm{~min}\right)$, followed by a final 10 -min extension step-using both no. 1 and no. 230 mers and Taq 1 polymerase (15) in a DNA thermal cycler (Cetus, Perkin-Elmer Corp., Norwalk, CT). The PCR-amplified products were electrophoresed through a 1.2\% agarose gel and subjected to Southern analysis (16-18) using ${ }^{32} \mathrm{P}$-labeled $105 \mathrm{mer}$ probes prepared as described above. In addition, a 1.2-kb amplified product identified in human brain was extracted from agarose gel, labeled with $\left[\alpha^{-3} \mathrm{P}\right] \mathrm{dCTP}$ by the random hexamer method, and used as a probe for Northern analysis.

In situ hybridization. The cellular localization of PTP mRNA was assessed using ${ }^{125}$ I-labeled 105 mer oligonucleotide probes corresponding to h-ICRF cDNA (see above) prepared by the random hexamer method using [ $\left.{ }^{125} \mathrm{I}\right]$ iodo-dCTP, or with antisense and sense cRNA probes (riboprobes) synthesized from the linearized bovine PTP 2-1 cDNA clone, and labeled with $\left[{ }^{35} S-\alpha\right.$-thio]UTP (DuPont New England Nuclear Research Products, Boston, MA). Formalin-fixed, paraffinembedded tissue sections ( $12 \mu \mathrm{m}$ thick) were dewaxed and rehydrated before use. The prehybridization protocol $(19,20)$ included sequential $0.2 \mathrm{~N} \mathrm{HCl}$ digestion, proteinase $\mathrm{K}$ digestion stopped with $4 \%$ paraformaldehyde, blocking with $0.2 \mathrm{M}$ glycine, acetylation with $0.1 \mathrm{M}$ triethanolamine and $0.05 \%$ acetic anhydride, and denaturation in $50 \%$ formamide/2 $\times$ SSPE at $50^{\circ} \mathrm{C}(19,20)$. When using ${ }^{35}$ S-labeled cRNA probes, additional blocking was accomplished by incubating the sections in PBS containing $10 \mathrm{mM}$ iodoacetamide, $10 \mathrm{mM}$ ethylmaleomide, and $10 \mathrm{mM}$ DTT before acetylation. The sections were hybridized with probe for $16 \mathrm{~h}$ at $50^{\circ} \mathrm{C}$ in buffer containing $50 \%$ formamide,
$10 \%$ polyethylene glycol $8000,5 \times$ SSPE, $5 \times$ Denhardt's solution, 10 $\mathrm{mM}$ DTT, and $100 \mu \mathrm{g} / \mathrm{ml}$ sheared, denatured salmon sperm DNA. The slides were washed in $50 \%$ formamide $/ 2 \times$ SSPE $/ 0.5 \%$ Triton-X 100 (four times, $15 \mathrm{~min}$ each) at $50^{\circ} \mathrm{C}$ in a shaking water bath, followed by $2 \times$ SSPE, and then $0.5 \times$ SSPE. When tissues were hybridized with cRNA probes, they were treated with RNAse $\left(50 \mu \mathrm{g} / \mathrm{ml}, 37^{\circ} \mathrm{C}, 30 \mathrm{~min}\right)$ after the formamide washes. The sections were dehydrated in graded alcohols containing $0.3 \mathrm{M}$ ammonium acetate and then subjected to autoradiography using NTB-2 emulsion (Eastman Kodak Co.).

Immunohistochemistry. PTP immunoreactivity was examined in formalin-fixed, paraffin-embedded sections of postmortem cerebral cortex with underlying white matter from aged neurologically intact individuals (controls), patients with Alzheimer's disease or Down's syndrome plus Alzheimer's disease, infants of different ages, and one neurologically intact 16 -yr-old with cystic fibrosis patient, who died from respiratory failure and multiple embolic infarcts. The tissue sections ( $8 \mu \mathrm{m}$ thick) were dewaxed, hydrated, and immunostained with the no. 9 mouse MAb (2) to purified human PTP (3) by the avidinbiotin horseradish peroxidase method (Vector Laboratories, Inc., Burlingame, CA) according to the manufacturer's protocol.

Immunoradiometric assay to measure molecular size of PTP in the CNS: The molecular size of central nervous system PTP in CSF was assayed using a sensitive three-site immunoradiometric assay with MAbs 7 and 10 as captive antibodies on the solid-phase support and ${ }^{125}$ I-labeled MAb 9 as the tracer (2). Normal pancreatic fluid and neet CSF were analyzed on $15 \%$ polyacrylamide gels in the presence of sodium dodecyl sulfate (SDS-PAGE). After electrophoresis, the wet gels were cut into 2-mm fractions using a gel slicer. Proteins were eluted from the gel fractions by shaking $24-72 \mathrm{~h}$ at $4^{\circ} \mathrm{C}$ with $1 \mathrm{ml}$ of PBS containing $1 \% \mathrm{BSA}$ and $0.2 \% \mathrm{NaN}_{3}$. The eluates were analyzed for PTP binding activity by immunoradiometric assay (M-IRMA). Prestained protein molecular weight markers (Bio-Rad Laboratories, Richmond, CA) were used to estimate the apparent molecular weight of the material with PTP immunoreactivity.

\section{Results}

27 clones with insert sizes between 0.65 and $0.9 \mathrm{~kb}$ were identified from $6 \times 10^{4}$ plaques, two of which $(0.65 \mathrm{~kb}, 3-2$ clone and $0.85 \mathrm{~kb}, 2-1$ clone) were used to prepare probes for cloneto-clone Southern hybridization after EcoRI digestion. The 3-2 clone hybridized only with itself and was not studied further. The 2-1 clone, which hybridized with 20 of the other clones, contained a 790-bp sequence corresponding to a single continuous open reading frame beginning with an initiating methionine codon in position 35 and terminating at a stop codon in position 560 (Fig. $1 \mathrm{~A}$ ). A noncoding region comprised the remainder of the clone, and was followed by a polyadenylation signal, indicating that the cDNA contained a fulllength transcript. The deduced amino acid sequence yielded a protein with a predicted molecular weight of $19.3 \mathrm{kD}$ and a pl of 5.7. Between residues 38 and 164, the predicted amino acid sequence matched the known partial sequence of the A and B chains of bovine PTP (5) with $98 \%$ identity. However, from the cDNA it appears that the A and B chains are synthesized as a single precursor molecule which is probably cleaved posttranslationally between alanine and isoleucine at residue 139 . Moreover, like many other secretory proteins, the PTP cDNA encodes a hydrophobic leader sequence with a potential cleavage site between alanine and arginine at residue 34 . The translated protein contains 6 potential phosphorylation sites, but no glycosylation motifs. 
GGTGTGCAACTCATCATGGACTTGGAACTAGGGATTCAGACCCACTATGGAAGGGGATAT TCTTCTCACAGCCCCAACCCAACCACTTCATTCTGACCTTCCCTCCTCCCCAGACTCAAT TCAGTCTCTTCTGTGTGTTCCATAACCTGACTTTGCAAAGTTCACAATAAAAATATTAGT TTTCCTCGCC

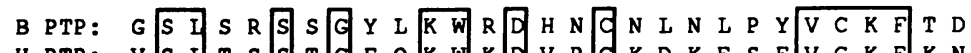
H PTP: V S I T S S T G F O K W K D V P O K D K F F S F V C K F K N H ICRF: $V$ S I T $S S S T$ T $F$ Q K W K D V P G E D K F S F V V C K F K K E S G T D D F N V W N

Figure 1. (A) CDNA and deduced amino acid sequence of bovine PTP. A bovine pancreatic cDNA library ligated into the EcoRI site of the $\lambda$ ZAP cloning vectors was screened with polyclonal antibody to purified PTP, and this $2-1$ insert was sequenced by the dideoxynucleotide chain-termination method using plasmid DNA and T7 polymerase. This full-length clone has one continuous open reading frame beginning from the first methionine codon and a polyadenylation signal. There is a hydrophobic leader sequence, potential cleavage sites at residues 36 and 138, and 6 possible phosphorylation sites. (B) Comparison of amino acid sequences of bovine PTP, the known portion of human PTP, and human ICRF. Human PTP and ICRF are nearly identical, and these share 45\% identity with bovine PTP, including the hydrophobic leader sequence, and with conservation of all seven cystine residues. 
Northern analysis of total cellular RNA using the 2-1 bovine PTP cDNA probe disclosed 0.8- and 0.4-kb transcripts in bovine pancreas (Fig. $2 \mathrm{~A}$ ). With prolonged exposure, a faint 0.8-kb hybridization signal was also detected in human pancreas but not human brain (data not shown). However, with reduced stringency of the final posthybridization wash $(0.5 \times$ SSPE $/ 0.1 \%$ SDS, $50^{\circ} \mathrm{C}$ ), a faint $1.2-\mathrm{kb}$ hybridization signal was detected by Northern analysis of RNA from brains with Alzheimer's disease, but not from brains of aged controls (Fig. 3). Dot-blot hybridization failed to demonstrate PTP transcripts in bovine salivary gland, heart, lung, and kidney, and rat pancreas and brain (Fig. $2 B$ ).

Comparison with other sequences in GeneBank Release 62.0 disclosed strong homology between the bovine PTP cDNA and amino acid sequences, and human and rat pancreatic ICRF (11), including conservation of the relative positions of all seven cystine residues among the three proteins. Moreover, the deduced amino acid sequence of the human ICRF proved to be identical with the amino acid sequence of human
PTP (Fig. 1 B), demonstrating that PTP and ICRF are the same molecules. Bovine PTP amino acid sequence shares $58 \%$ homology with the human form of the protein (3). This led us to synthesize two pairs of 60 mers with overlapping $5^{\prime}$ ends which were extended with Klenow to construct 105 mer oligonucleotides corresponding with nucleotides 97-201 and 313-417 of h-ICRF (11) to achieve more specific hybridization with PTP transcripts in human tissues.

Northern analysis using $\left[\alpha-{ }^{32} \mathrm{P}\right] \mathrm{dCTP}$-labeled $105 \mathrm{mer}$ probes generated with random oligonucleotide primers disclosed a highly abundant $\mathbf{0 . 9 - k b}$ transcript, as well as less abundant lower molecular weight species in human pancreas (Fig. $2 \mathrm{Ci}$ ). Primer extension assay using a synthetic $30 \mathrm{mer}$ oligonucleotide primer complimentary to the distal $3^{\prime}$ end (nucleotides 641-660) of the h-ICRF cDNA (11), plus a terminal EcoRI restriction site, confirmed the presence of $0.9-$ and 0.4-kb transcripts (Fig. 2 Cii). Northern analysis using the 105 mers as probes failed to demonstrate PTP mRNA in human brain. However, dot blot hybridization studies using
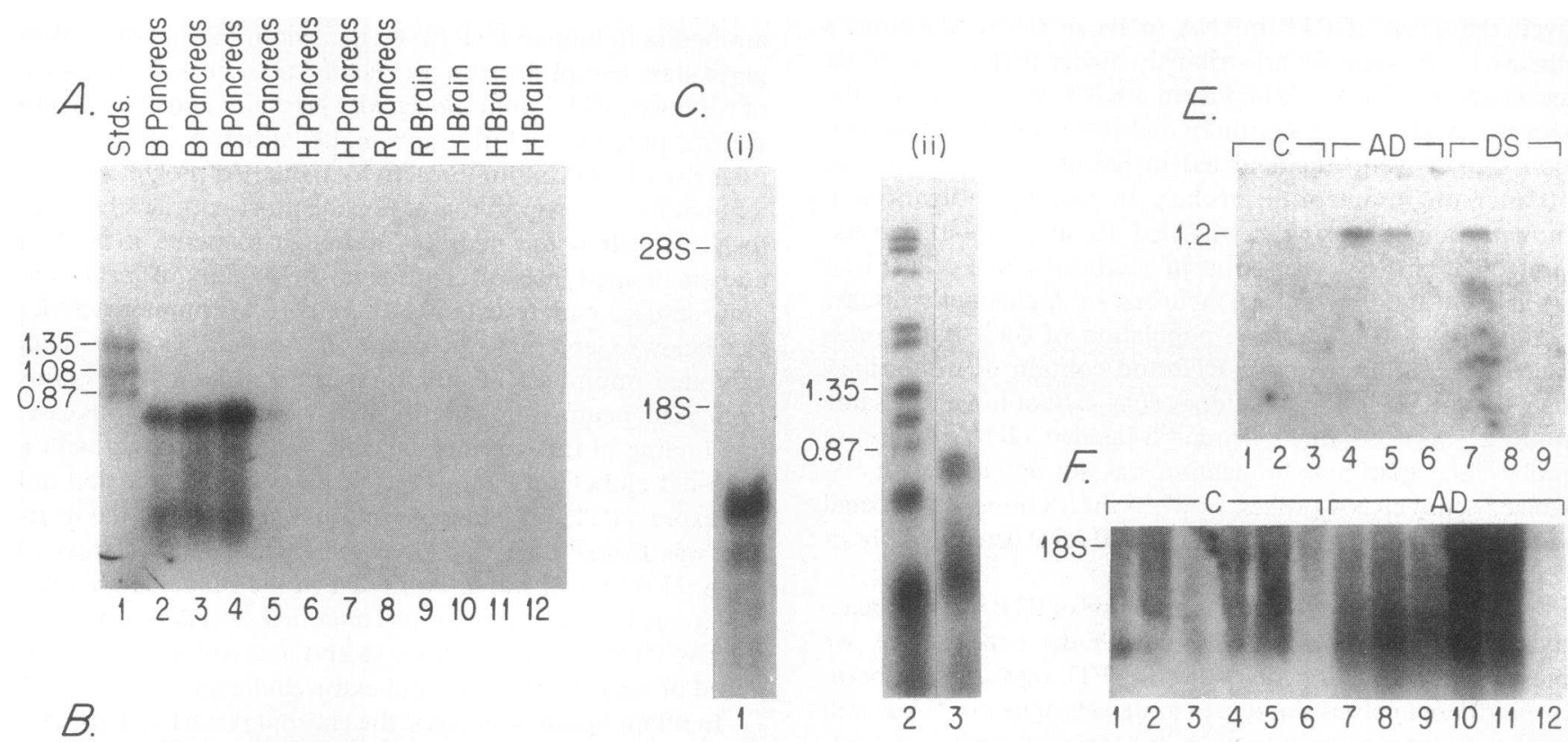

B.
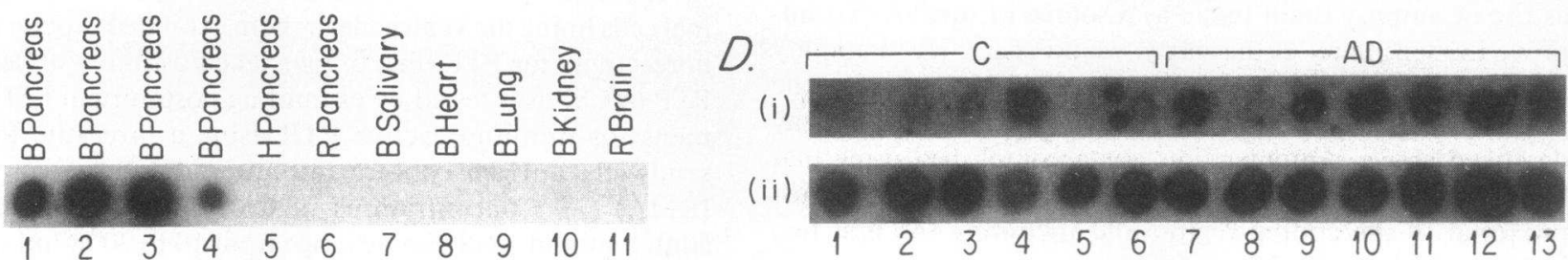

Figure 2. PTP mRNA in bovine and human tissues. $(A)$ Northern analysis of $10 \mu \mathrm{g}$ of total cellular RNA using the 2-1 cloned EcoRI insert encoding bovine-PTP labeled with $\left[{ }^{32} \mathrm{P}\right] \mathrm{dCTP}$ by the random priming method. $(B)$ Dot-blot analysis of $5 \mu \mathrm{g}$ of total cellular RNA using the same probe. $(\mathrm{Ci}$ ) Using two $105 \mathrm{mer}$ oligonucleotide probes corresponding to sequences encoding human PTP and human islet cell regeneration factor $(h-I C R F)$, a major transcript of $0.9 \mathrm{~kb}$, and a less abundant $0.4-\mathrm{kb}$ species were detected in human pancreas by Northern analysis. (Cii) Primer extension using a 30mer complimentary to the $3^{\prime}$ end of the h-ICRF cDNA demonstrated the 0.9- and 0.4-kb transcripts in pancreas. (D) Dot blot RNA hybridization studies using 105mer oligonucleotide probes demonstrated higher levels of PTP mRNA in six of seven Alzheimer's disease $(A D)$ brains compared with five of the six aged controls $(C)$. The lower row represents the same blot re-probed with a cDNA encoding $\beta$-actin. $(E)$ PCR-amplified cDNAs generated by reverse transcriptase assay using the same 30 mer employed in the primer extension assay, plus another corresponding to the 5 ' end of the cDNA (see Methods) were studied by Southern analysis with the 105mer of $60 \mathrm{mer}$ oligonucleotide probes. $(F)$ The 1.2-kb DNA amplified product when used as a probe in Northern analysis disclosed higher levels of 0.6- and 0.4-kb transcripts in Alzheimer's disease compared with aged controls. Lane 12 does not contain RNA. 


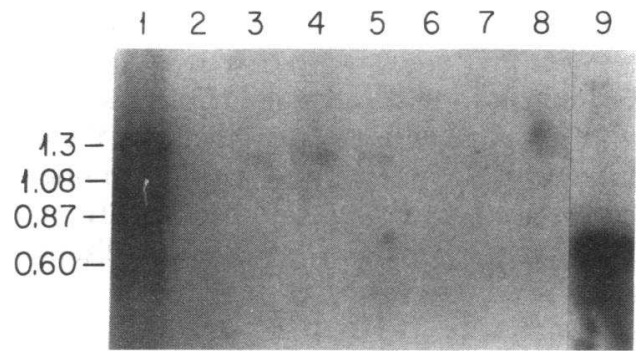

Figure 3. Demonstration of a 1.2-kb PTP-related transcript in human brain by Northern analysis. Each lane contains $\sim 10 \mu \mathrm{g}$ of total cellular RNA and the blot was probed with $\left[\alpha-{ }^{32} \mathrm{P}\right] \mathrm{dCTP}-\mathrm{la}-$ beled 2-1 bovine PTP cloned insert, and washed at a lower stringency compared with the blots in Fig. 2. Lane 1, molecular weight markers. Lanes 2, 6, and 7 contain control brain RNA. Lanes 3-5 contain RNA from Alzheimer's disease brains, and lane 8 contains RNA from an individual with Down's syndrome plus Alzheimer's disease. Lane 9 contains bovine pancreatic RNA.

105mer probes did demonstrate PTP mRNA in human brain, but at much lower levels compared with the pancreas. Moreover, the levels of PTP mRNA in six of seven Alzheimer's disease brains were found strikingly higher than in five of six aged controls. The levels of $\beta$-actin mRNA were similar for the two groups (Fig. 2 D). Northern and RNA dot blot hybridization signals were not detected in bovine tissues using the 105 mer oligonucleotide probes. In situ hybridization of human pancreas using ${ }^{125}$ I-labeled 105 mer probes demonstrated PTP mRNA transcripts in nearly all acinar cells (Fig. 4 $A)$ as well as in pyramidal neurons in Alzheimer's disease brains (Fig. $4 C$ ), the same population of cells that express increased immunoreactive PTP and contain neurofibrillary tangles, but not in human kidney (Fig. $4 \mathrm{~B}$ ) or lung. The same findings were obtained using ${ }^{35} \mathrm{~S}$-labeled cRNA antisense probes, and specific hybridization was not observed with ${ }^{35} \mathrm{~S}$ labeled sense cRNA probes, or when the sections were treated with RNAse A $\left(50 \mu \mathrm{g} / \mathrm{ml}\right.$ at $37^{\circ} \mathrm{C}$ for $\left.30 \mathrm{~min}\right)$ before to hybridization (data not shown).

Given the millionfold lower amounts of PTP immunoreactivity in human brain compared with the pancreas (2), we presumed that the difficulty detecting PTP transcripts in brain by Northern analysis was due to low levels of its mRNA as well as use of autopsy brain tissue as a source of mRNA. To improve the sensitivity of this assay, we utilized PCR to amplify specific cDNAs generated by reverse transcriptase using the same 30mer (no. 1) employed in the primer extension assay described above. Amplification was accomplished using that $30 \mathrm{mer}$, and another (no. 2) complementary to the $5^{\prime}$ end, just proximal to the coding region and including the first two codons as detailed in Methods. The amplified products were separated by electrophoresis and studied by Southern hybridization. Using 3 '-end labeled $60 \mathrm{mer}$ probes (used to generate the 105 mers) or 105 mer probes made by the random priming method, a hybridization signal at $1.2 \mathrm{~kb}$ was detected in brain samples from a patient with Alzheimer's disease and an infant with Down's syndrome, but not from an aged control (Fig. 2 $E$ ). Since amplification of genomic DNA could not be ruled out in this experiment, we performed primer extension assays using the 30 mer complimentary to the $3^{\prime}$ end of the h-ICRF cDNA. In these studies we demonstrated 0.9- and 0.4-kb transcripts in both Alzheimer's disease and control brains, as well as a 1.2-kb transcript in one Alzheimer's disease brain (data not shown). The 1.2-kb amplified fragment which hybridized with the 105 mer and 60 mer probes was extracted from agarose and labeled by the random oligonucleotide priming. Northern analysis with this probe demonstrated transcripts of 0.9 and $0.4 \mathrm{~kb}$ in human pancreas (data not shown). In diseased and normal brains, 1.2- and 0.9-kb transcripts were also present but in very low levels. However, an interesting finding with respect to Alzheimer's disease was the detection of an additional 0.6-kb transcript, and increased expression of both the 0.4- and 0.6-kb mRNAs compared with aged controls (Fig. $2 F$ ).

RNA dot blot hybridization studies demonstrated higher levels of PTP expression in normal infant brain compared with aged adults. This observation prompted us to examine PTP immunoreactivity during development. Paraffin-embedded sections of brain from infants born prematurely at $24,27,29$, 32,34 , and 36 wk of gestation and who died within the perinatal period, full-term infants who died at 1 or $6 \mathrm{mo}$ of age, and a 16-yr-old patient, were simultaneously immunostained (along with tissue from aged controls, patients with Alzheimer's disease and individuals with Down's syndrome) with monoclonal antibodies to human PTP (2) by the avidin-biotin horseradish peroxidase complex method (Vector Laboratories). At $24 \mathrm{wk}$ of gestation, PTP immunoreactivity was faint and restricted to neuritic processes in future grey matter structures (Fig. 5). The intensity of PTP immunoreactivity increased progressively as a function of age up to 6 mo. For the most part, labeling was localized within the neuropil, although scattered individual and small aggregates of neurons in the vicinity of focal ischemic damage manifested intense perikaryal immunoreactivity (see below). Cerebral tissue from the 16-yr-old patient overall exhibited minimal PTP immunoreactivity, similar to brains from aged, neuropathologically intact controls (2). In this case, one finding of interest was the observation associated with a 2-wk-old embolic infarct; the neurons were necrotic and did not express PTP, although the immunoreactivity in the neuropil was higher than that observed in more intact areas of brain. However, it was striking that in the immediately adjacent gyrus most of the neurons contained abundant immunoreactive PTP within the perikarya and neuropil which is comprised of neuritic processes and extracellular space.

In infant brains of all ages, the choroid plexus and ependymal cells lining the ventricular system exhibited intense immunoreactivity for PTP (Fig. 6, top). The possibility of detecting PTP in CSF was tested by examining postmortem CSF specimens for immunoreactive PTP using a three-site forward sandwich, antigen capture immunoradiometric assay (MIRMA) (2). Concentrations in CSF derived from normal adults without CNS disease range from 10 to $30 \mathrm{ng} / \mathrm{ml}(n=5)$. The molecular weight of PTP in CSF was estimated by SDSPAGE coupled with antigen capture immunoradiometric assay of PTP eluted from the gel slices. In CSF, the PTP-like protein was larger than the one observed in the pancreas (17-20 vs. 14-kD, respectively) (Fig. 6, bottom), but the same as that observed in brain tissue (2).

\section{Discussion}

A complete cDNA encoding bovine PTP has been cloned. The deduced amino acid sequence indicates the presence of a hy- 

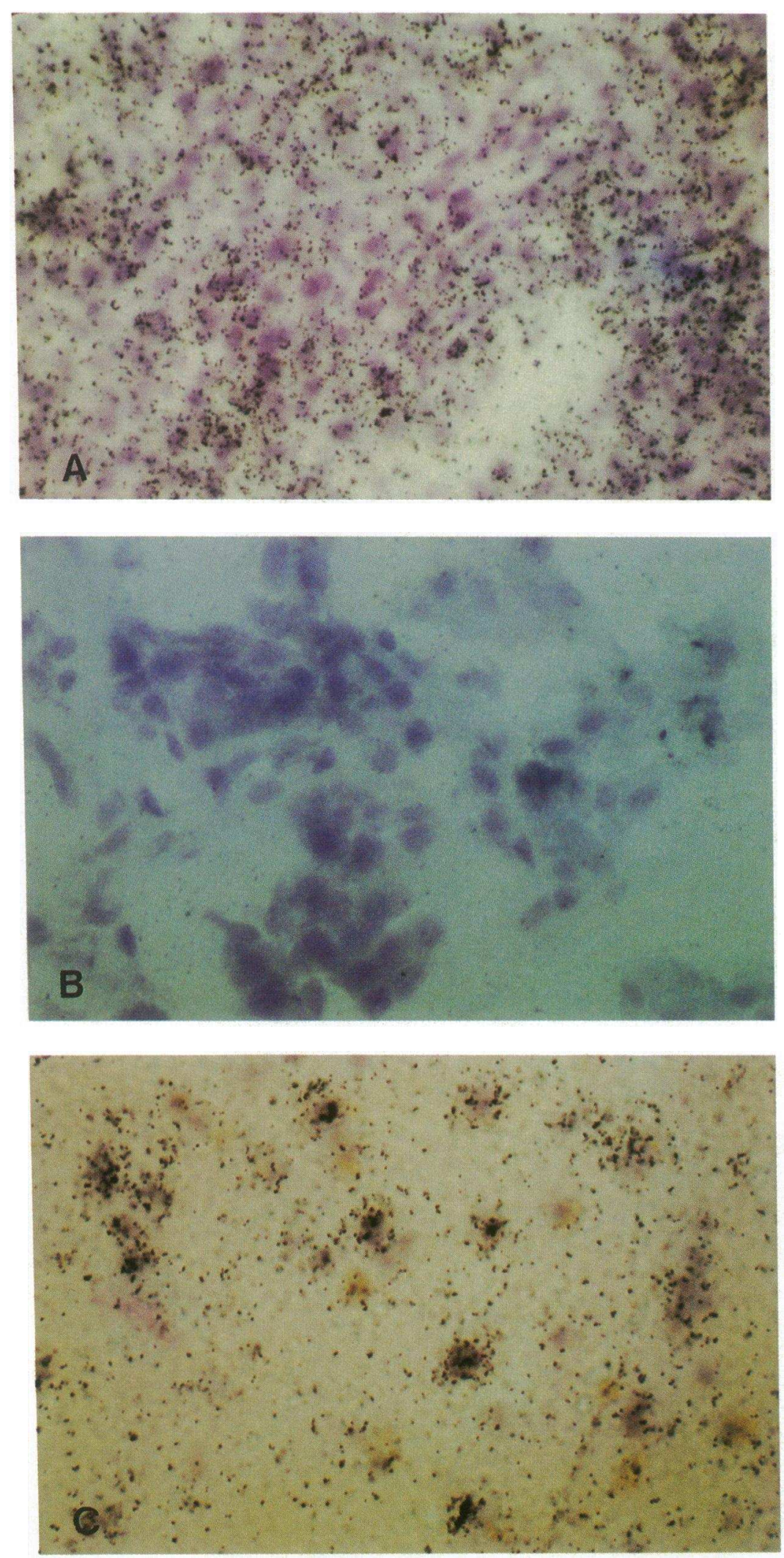

Figure 4. In situ hybridization of human pancreas, kidney, brain using ${ }^{125}$ I-labeled 105 mer oligonucleotide probes. Specific hybridization grains are present over virtually all acinar cells $(A)$, in contrast to the absence of signal in kidney $(B)$. In Alzheimer's disease brain $(C)$, specific hybridization signals were present mainly over pyramidal neurons, the same cells which contain high levels of immunoreactive PTP and neurofibrillary tangles. drophobic leader sequence. Although the protein consists of two chains, A and B, it probably is synthesized as a single peptide and cleaved posttranslationally. Hybridization studies with RNA from normal adult bovine tissues suggest that ex- pression is restricted to the pancreas. The relatively weak signal observed when human tissues were hybridized with the bovine cDNA probe was probably due to phylogenetic diversity in PTP mRNA sequences. 

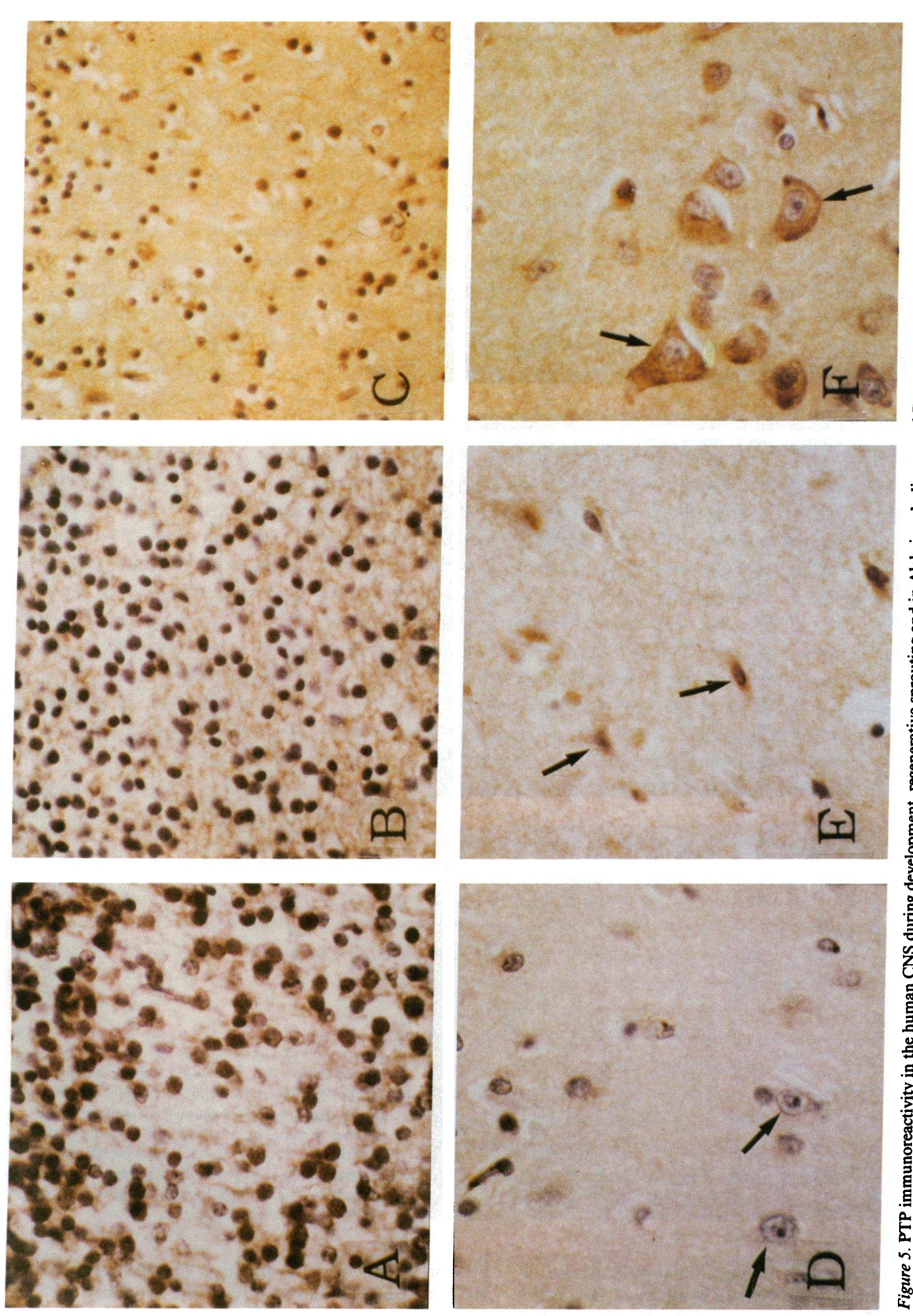

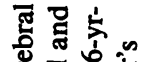

过

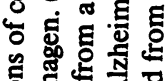

然

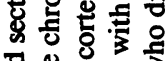

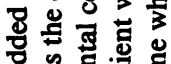

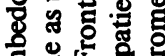

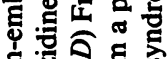

为

究

ن ह

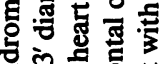

हैं 운

क

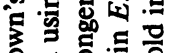

के ठ웡

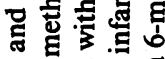

急

尊

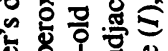

政

产

制

密 㩆

동

o. 흉 है

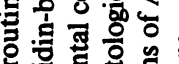

을

员里

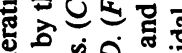

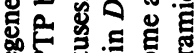
远和

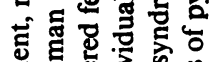

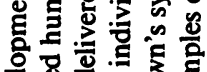
\&

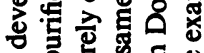

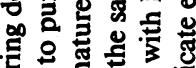
政 绐

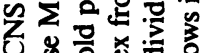

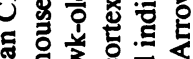

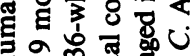

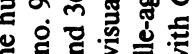
क

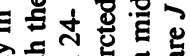

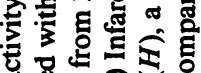
记

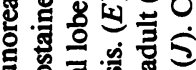
要 要递尊 의 政

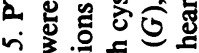

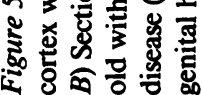



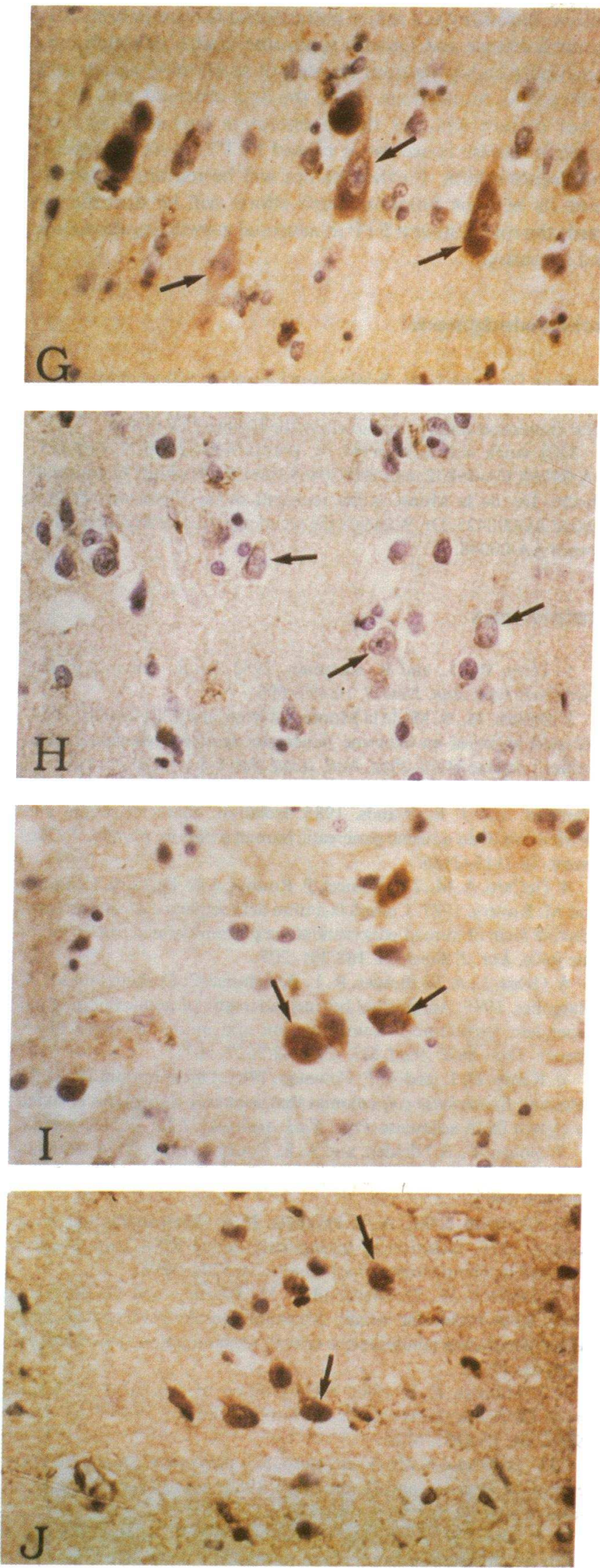

Figure 5 (Continued)
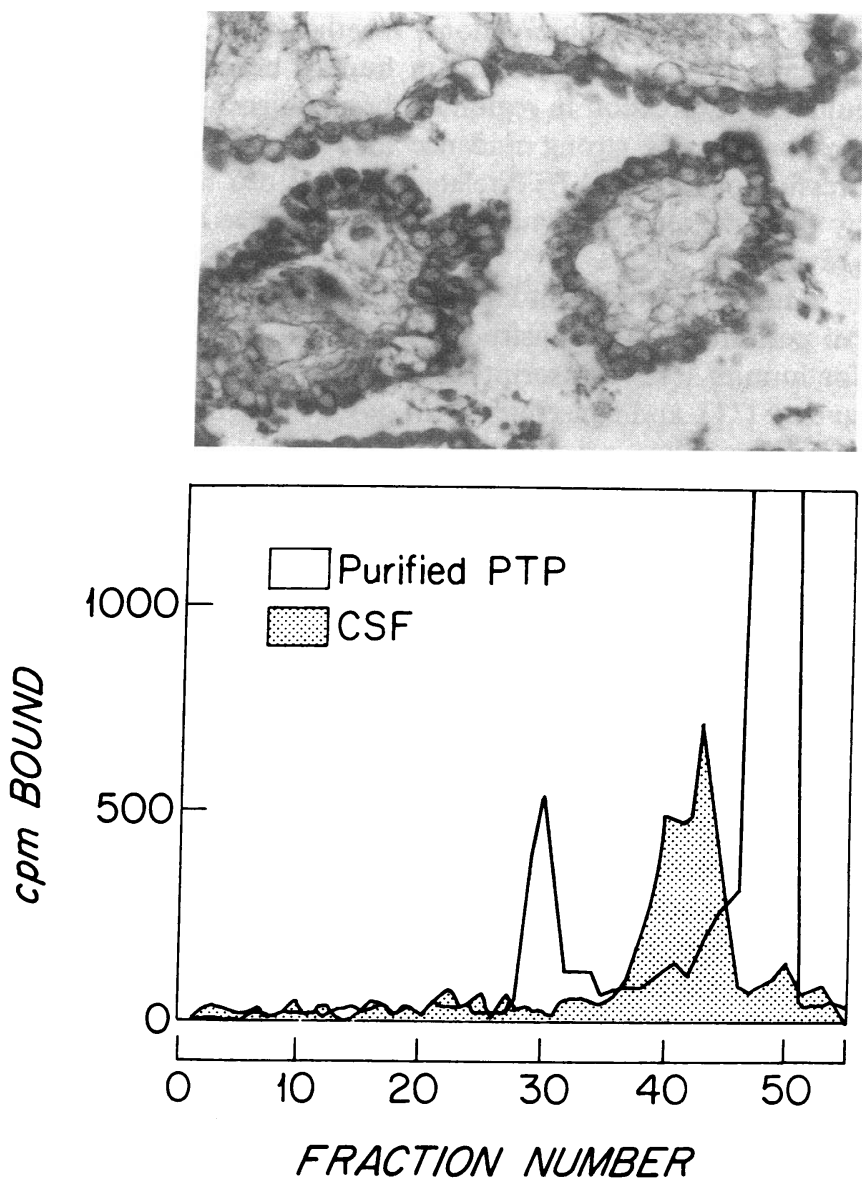

Figure 6. (Top) PTP immunoreactivity in human choroid plexus and CSF. Paraffin-embedded sections of choroid plexus were immunostained as described in Fig. 5 except that diaminobenzidine was coprecipitated with nickle chloride. (Bottom) Molecular size of central nervous system PTP in CSF of a normal individual using a sensitive three-site immunoradiometric assay with MAbs 7 and 10 as captive antibodies on the solid-phase support and ${ }^{125}$ I-labeled MAb 9 as the tracer. Normal pancreatic fluid, and neet CSF were analyzed on $15 \%$ polyacrylamide gels in the presence of sodium dodecyl sulfate (SDSPAGE). After electrophoresis, the wet gels were cut into 2-mm fractions using a gel slicer. Proteins were eluted from the gel fractions by shaking 24-72 h at $4^{\circ} \mathrm{C}$ with $1 \mathrm{ml}$ PBS containing $1 \%$ BSA and $0.2 \%$ $\mathrm{NaN}_{3}$. The eluates were analyzed for PTP binding activity by M-

IRMA. Prestained protein molecular weight markers (Bio-Rad Laboratories) were used to estimate the apparent molecular weight of the material with PTP immunoreactivity.

It was of interest to discover that bovine PTP cDNA shares a high degree of homology with another gene cloned from regenerating pancreatic islets, ICRF, and that the known amino acid sequence of human PTP protein is identical to that of human ICRF. What is curious about this molecule is that it is expressed at high levels in the normal exocrine pancreas, and not at all, or only at very low levels in normal islet cells judged by immunohistochemistry and in situ hybridization findings in this study, and Northern analysis in the work by Terazono et al. (11). Recently, the same group published the genomic sequence of the human reg gene which encodes ICRF/PTP, and also found expression of identical transcripts in colorectal 
cancer (21). These observations, together with the developmentally regulated expression in human brain, and focally enhanced expression in regions of brain adjacent to acute infarction provide strong evidence that the tissue-specific expression of PTP and PTP-related proteins can be modulated by both normal and pathological states concerned with cell growth.

The observation that PTP and ICRF proteins were identical permitted us to construct oligonucleotide probes specific for human PTP transcripts using the published cDNA sequence (11), and consequently improve the hybridization signal. In addition, we were able to synthesize oligonucleotide primers for use in primer extension assays and PCR amplification of PTP transcripts. With information culled from several different assays, it was clear that in both bovine and human pancreas there was a major 0.9-kb transcript as well as several minor species corresponding to the PTP cDNA. This may be due to a family of related gene transcripts, differential splicing of a single gene, or degradation of a parent species.

In Alzheimer's disease brains, the levels of PTP mRNA were strikingly higher than in aged controls. In situ hybridization helped confirm high-level expression of PTP-related transcripts in the same population of neurons that is diseased and contains neurofibrillary tangles in Alzheimer's disease. Like the pancreas, multiple PTP-related transcripts were observed in brain. The fact that the same size transcripts were present in brain and pancreas suggests the mRNA species are similar in the two tissues. This is corroborated by the finding that in Alzheimer's disease brains, there is a 30 -fold excess accumulation of a protein that shares three antigenic epitopes with PTP (2). However, the larger size protein in brain tissue and CSF suggests that the final translated product may be different from that in the pancreas. The increased levels of a $0.6-\mathrm{kb}$ transcript in $\mathrm{AD}$ brains is of interest because this size transcript was not observed in the pancreas or control brains, and may point toward an abnormality, e.g., mutation, associated with Alzheimer's disease. Additional cloning and sequencing data will answer this question. Overexpression of PTP-related transcripts in neurons could account for the striking intraneuronal accumulations of immunoreactive PTP (2). The mechanism by which overexpression of a gene structurally homologous to an exocrine pancreatic secretory protein contributes to the pathogenesis of AD is unknown.

High-level PTP-like immunoreactivity in fetal and infant brain, combined with the very low or virtually absent immunoreactivity in a 16-yr-old and several normal elderly adult brains suggest that PTP expression in the central nervous system (CNS) is developmentally regulated. However, expression of PTP-like immunoreactivity can be modulated by environmental or extrinsic factors such as injury as suggested by this study. Precisely what function PTP-related transcripts and proteins serve in the CNS is unclear, but the resurgent activity associated with regenerative sprouting (recent infarction), the higher levels of PTP-related mRNAs in developing brains which are undergoing intense restructuring of synapses compared with mature brains which remodel at much lower rates, and the structural identity of the human PTP protein with the deduced amino acid sequence of islet cell regeneration factor suggest that thread proteins, both neural and pancreatic forms may be associated with cell growth. In the mature CNS, PTP expression might be related to neuronal sprouting and regen- eration. Sprouting is a major pathological feature in both Alzheimer's disease and Down's syndrome brains, although fundamentally highly aberrant because of its abortive nature and inefficacious connections. From the data obtained thus far, it is not certain whether the regenerative sprouting in Alzheimer's disease causes or is caused by PTP over-expression and accumulation. Further studies will be required to determine its biologic function. Such efforts will be directed towards the role of neural PTP in neuronal growth, regeneration, and sprouting.

\section{Acknowledgment}

We thank Dr. Louis Lang, Washington University School of Medicine, St. Louis, MO, for generously providing the bovine pancreatic $\operatorname{cDNA} \lambda$ ZAP expression library used to clone the bovine PTP cDNA.

This work was supported by grants AA-02666, CA-35711, AA-08169, CA-49832, and HD-20469 from the National Institutes of Health. Dr. de la Monte is the recipient of the Physician Scientist Award AG000425. Dr. Wands is the recipient of the Research Scientist Award AA-00048.

\section{References}

1. Terry, R. D., and R. Katzman. 1983. Senile dementia of the Alzheimer type. Ann. Neurol. 14:497-506.

2. Ozturk, M., S. M. de la Monte, J. Gross, and J. R. Wands. 1989. Elevated levels of an exocrine pancreatic secretory protein in Alzheimer's disease brain. Proc. Natl. Acad. Sci. USA. 86:419-423.

3. Gross, J., R. I. Carlson, A. W. Brauer, M. N. Margolies, A. L. Warshaw, and J. R. Wands. 1985. Isolation, characterization, and distribution of an unusual pancreatic human secretory protein. J. Clin. Invest. 76:2115-2126.

4. DeCaro, A. M., J. J. Bonicel, P. Rouimi, J. D. De Caro, H. Sarles, and M. Rovery. 1987. Complete amino acid sequence of an immunoreactive form of human pancreatic stone protein isolated from pancreatic juice. Eur. J. Biochem. 168:201-207.

5. Gross, J., A. W. Brauer, R. L. Bringhurst, C. Corbett, and M. N. Margolies. 1985. An unusual bovine pancreatic protein exhibiting pH dependent globule-fibril transformation and unique amino acid sequence. Proc. Natl. Acad. Sci. USA. 82:5627-5631.

6. Kemp, D. J., and A. F. Cowman. 1981. Direct immunoassay for detecting Escherichia coli colonies that contain polypeptides encoded by cloned DNA segments. Proc. Natl. Acad. Sci. USA. 78:4520-4524.

7. Sanger, F., S. Nicklen, and A. R. Coulson. 1977. DNA sequencing with chain-terminating inhibitors. Proc. Natl. Acad. Sci. USA. 74:5463-5467.

8. Chirgwin, J. M., A. E. Pryzbyla, R. J. MacDonald, and W. J. Rutter. 1979. Isolation of biologically active RNA from sources enriched in ribonuclease. Biochemistry. 18:5294-5298.

9. Lehrach, H., D. Diamond, J. M. Wozney, and H. Boedtker. 1977. RNA molecular weight determinations by gel electrophoresis under denaturing conditions: a critical reexamination. Biochemistry. 16:4743-4756.

10. Thomas, P. S. 1980. Hybridization of denatured RNA and small DNA fragments transferred to nitrocellulose. Proc. Natl. Acad. Sci. USA. 77:5201-5216.

11. Terazono, K., H. Yamamoto, S. Takasawa, K. Shiga, Y. Yonemura, Y. Tochino, and H. Okamoto. 1988. A novel gene activated in regenerating islets. J. Biol. Chem. 263:2111-2114.

12. Jones, K. A., K. R. Yamamoto, and R. Tjian. 1985. Two distinct transcription factors bind to the HSV thymidine kinase promotor in vitro. Cell. 42:559-572.

13. McKnight, S. L., and R. Kingsbury, 1982. Transcription con- 
trol signals of a eukaryotic protein-coding gene. Science (Wash. DC). 217:316-324.

14. Chehab, F. F., M. Doherty, S. Cai, Y. W. Kan, S. Cooper, and E. M. Rubin. 1987. Detection of sickle cell anaemia and thalassaemias. Nature (Lond.). 329:293-294.

15. Kogan, S. C., M. Koherty, and J. Gitschier. 1987. An improved method for prenatal diagnosis of genetic diseases by analysis of amplified DNA sequences: application to hemophilia A. N. Engl. J. Med. 317:985-990.

16. Southern, E. M. 1975. Detection of specific sequences among DNA fragments separated by gel electrophoresis. J. Mol. Biol. 98:503-517.

17. Meinkoth, J., and G. Wahl. 1984. Hybridization of nucleic acids immobilized on solid supports. Anal. Biochem. 138:267-284.
18. Reed, K. C., and D. A. Mann. 1985. Rapid transfer of DNA from agarose gels to nylon membranes. Nucleic Acids Res. 13:72077221.

19. Cox, K. H., D. V. DeLeon, L. M. Angerer, and R. C. Angerer. 1984. Detection of mRNAs in sea urchin embryos by in situ hybridization using asymmetric RNA probes. Dev. Biol. 101:485-502.

20. Augulowitxch, A., M. F. Utset, C. P. Hart, W. McGinnis, and F. H. Ruddle. 1986. Spatial restriction in expression of a mouse homeobox locus within the central nervous system. Nature (Lond.). 320:328-335.

21. Watanabe, T., H. Yonekura, K. Terazono, H. Yamamoto, and H. Okamoto. 1990. Complete nucleotide sequence of human reg gene and its expression in normal and tumoral tissues. J. Biol. Chem. 265:7432-7439. 